\title{
Metaplastic Carcinoma of the Breast: p53 Analysis Identified the Same Point Mutation in the Three Histologic Components
}

\author{
Xiaojuan Wang, M.D., Ichiro Mori, M.D., Ph.D., Weihua Tang, M.D., Qifeng Yang, M.D., \\ Misa Nakamura, Ph.D., Yasushi Nakamura, M.D., Ph.D., Misako Sato, B.S., Takeo Sakurai, M.D., Ph.D. \\ Kakudo Kennichi, M.D., Ph.D. \\ Department of Pathology (XW, IM, WT, MN, YN, MS, KK), Wakayama Medical University, Japan; and \\ Department of Surgery (QY, TS), Affiliated Kihoku Hospital, Wakayama Medical University, Japan
}

\begin{abstract}
A rare case of metaplastic carcinoma of the breast with both squamous metaplasia and cartilaginous metaplasia was reported. Histologically, the neoplasm revealed complex features, which were consisting of invasive ductal carcinoma, squamous carcinomatous component and chondrosarcomatoid component. Gradual transition of each component was recognized microscopically. p53 mutation analysis disclosed the same point mutation in three histologically different components, but not in the normal epithelium. Based on the morphologic findings, immunohistochemical findings and the p53 mutation analysis, we concluded that these three components in the tumor originated from the same duct progenitor cells.
\end{abstract}

KEY WORDS: Breast cancer, cartilaginous metaplasia, Metaplastic carcinoma, p53, Squamous metaplasia.

Mod Pathol 2001;14(11):1183-1186

Metaplastic carcinoma of the breast is rare and it has been classified into two groups: squamous metaplasia (3.7\% of all breast cancers) (1) and heterologous metaplasia $(0.2 \%)(2)$. The exact histogenesis whether they are from a single progenitor cell or not is an issue to be solved. Metaplastic carcinoma that contains both of the types of component is extremely rare $(3,4)$. Among the routine examination of 492 breast cancers in our depart-

Copyright $(2001$ by The United States and Canadian Academy of Pathology, Inc.

VOL. 14, NO. 11, P. 1183, 2001 Printed in the U.S.A.

Date of acceptance: July 21, 2001.

The study was supported by Grant-in-Aid for Scientific Research (B) (\#10045073) from the ministry of education. Xiaojuan Wang received a scholarship form Japan-China Medical Association.

Address reprint requests to: Xiaojuan Wang, M.D., Department of Pathology, Wakayama Medical University, 811-1 Kimiidera, Wakayama City, Japan 641-0012; e-mail: wang-xj@mail.wakayama-med.ac.jp; fax: 81-073-446-4825. ment from 1998 to 2000, only one such case was observed, which coexhibited both squamous and cartilaginous metaplasia in one tumor. Based on histopathologic finding and immunohistochemical staining, we speculated that the three components; ductal carcinoma, squamous component and cartilaginous component in the tumor might be originated from the same progenitor cell. To prove this hypothesis, a p53 mutation analysis was performed on the breast tumor.

\section{CASE REPORT}

\section{Clinical History}

A 52-year-old woman noticed a rapidly growing mass in her right breast, involving the upper, lower outer quadrant and center of the breast. The tumor was diagnosed as a malignant tumor (Class V) by aspiration cytology, where a few large cells with high polymorphism scattered or in small nests. The patient underwent right glandectomy with axillary lymph node dissection. She was in good condition at the latest follow-up, 6 months postoperatively.

\section{Gross Examination}

The resected breast tissue and dissected lymph nodes were submitted after formalin fixation to our laboratory. Serial cuts disclosed $4 \times 2 \mathrm{~cm}$ tumor mass at the outer and center regions of the breast. The lesion appeared firm and solid with irregular borders, invading into fatty tissue without involvement of skin and muscle tissue. Compared with the common breast cancer, the cut surface seemed to be smoother and moister. No hemorrhage or necrosis was seen on the cut surface. 
Histopathology

Microscopically, the tumor was mainly composed of a typical papillotubular pattern of invasive ductal carcinoma, while foci of squamous carcinomatous element and chondrosarcomatoid component were intermingled in the tumor. The squamous area showed apparent keratinization and intercellular bridge. Gradual transition and close relation among the three different morphologies were identified (Fig. 1). All the 16 dissected lymph nodes were free from the metastatic cancer.

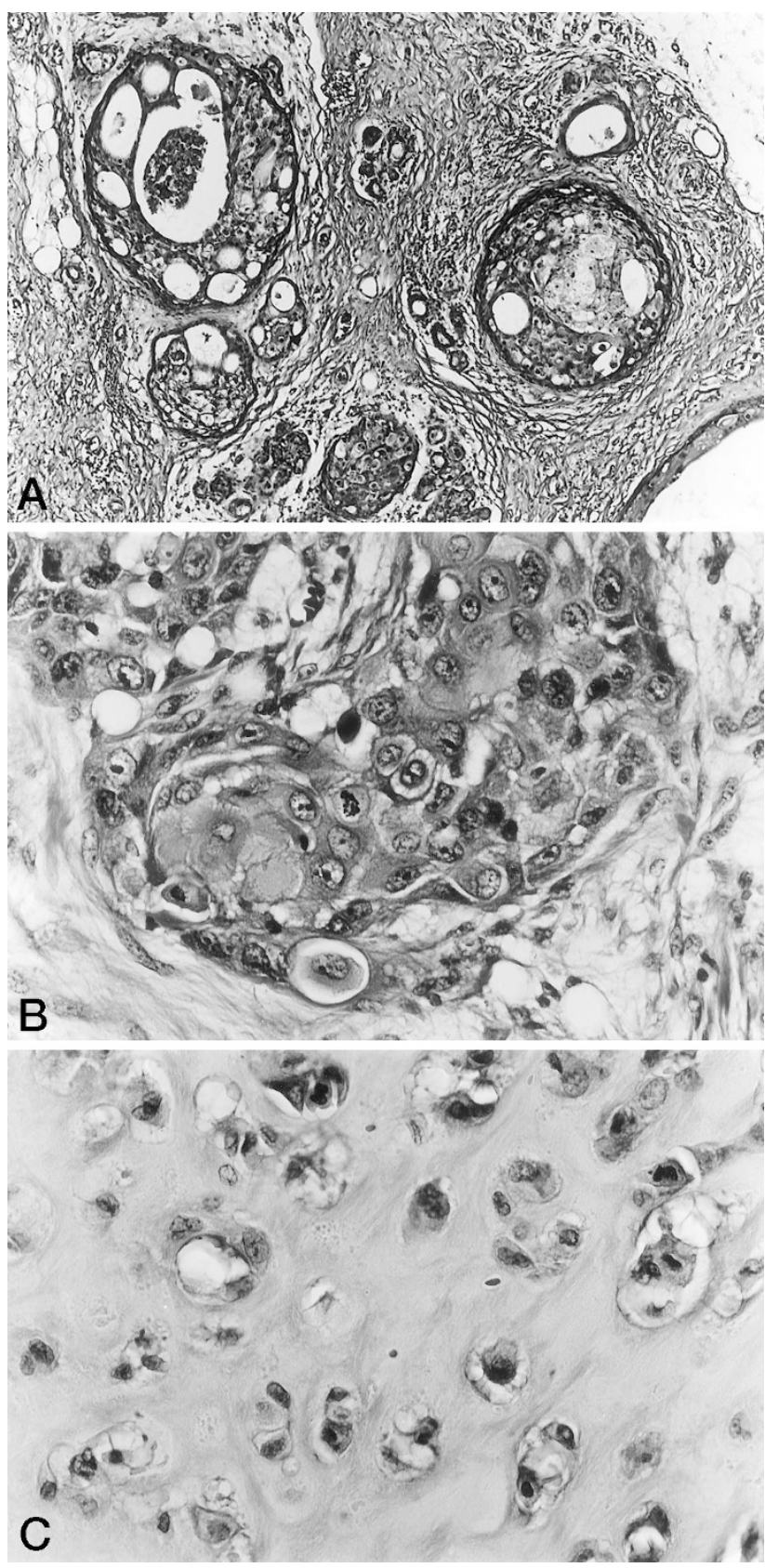

FIGURE 1. Histologic features of the metaplastic carcinoma of the breast (H\&E staining). A, Ductal carcinoma $(\times 100)$; B, squamous carcinomatous component $(\times 400)$; and $\mathbf{C}$, chondrosarmatoid component $(\times 400)$

\section{MATERIALS AND METHODS}

\section{Immunohistochemistry}

Immunohistochemical staining was performed on the breast tumor using the LSAB method (DAKO Cor., Carpinteria, CA). The antibodies used were listed in Table 1. Except for epithelial membrane antigen, smooth muscle actin, and S-100, the sections were pretreated with microwave (citric acid buffer, $\mathrm{pH}$. 6.0) for antigen retrieval.

\section{Microdissection and p53 Mutation Analysis}

Six sections of $10 \mu \mathrm{M}$ thickness were cut from the formalin-fixed, paraffin-embedded tumor. Invasive ductal carcinoma, squamous carcinomatous nest, chondrosarcomatoid element were micro-dissected, respectively, after hematoxylin and eosin staining. The normal ductal epithelium and stroma were also examined. The microdissected tissue were applied into $60 \mu \mathrm{L}$ proteinase $\mathrm{K}$-digestion buffer and incubated at $56^{\circ} \mathrm{C}$ overnight (5). The samples were centrifuged and the supernatants were treated at $95^{\circ} \mathrm{C}$ for 10 minutes. PCR amplification was performed in a total volume of $50 \mu \mathrm{L}$ of reaction mixture involving $5 \mu \mathrm{L}$ these lysate in a thermal cycler (Perkin-Elmer, Norwalk CT, Gene Amp PCR System 9700) for 40 cycles. The primers for exon 5-8 and the condition for each cycle were described previously (6). The amplified DNA was subjected to direct sequencing using an autosequencer model 310 (Applied Biosystems, Model 310, Foster City, CA).

\section{RESULTS}

\section{Immunohistochemical Results}

Keratin, cytokeratin 13, and epithelial membrane antigen were expressed in three elements of the tumor. Positivity for cytokeratin 17 and p63 were only seen in the normal duct epithelium and the squamous component, but not identified in the

TABLE 1. The Dilution and List of Antibodies

\begin{tabular}{llcc}
\hline \multicolumn{1}{c}{ Antibody } & \multicolumn{1}{c}{ Clone } & Pretreatment & Dilution \\
\hline Keratin & KL-1 & + & $1: 100$ \\
Cytokeratin 17 & Ks17.E3 & + & $1: 20$ \\
Cytokeratin 13 & Ks13.1 & + & $1: 20$ \\
EMA & E29.(1). & - & $1: 100$ \\
SMA & 1A4 & - & $1: 400$ \\
Vimentin & Vim3B4.(1) & + & $1: 100$ \\
S-100 & Poly & - & $1: 400$ \\
ER & 1D5.(1). & + & $1: 400$ \\
c-erb-B-2 & CB11 & + & $1: 100$ \\
Bcl-2 & Bcl-2/100/D5 & + & $1: 80$ \\
p53 & DO-7 & + & $1: 100$ \\
Ki-67 & MIB-1 & + & $1: 100$ \\
p63 & OP132T & + & $1: 400$ \\
\hline
\end{tabular}

EMA, epithelial membrane antigen; SMA, smooth muscle actin; ER, estrogen receptor. 
TABLE 2. Immunohistochemical Results in This Case

\begin{tabular}{|c|c|c|c|c|c|c|c|c|c|c|c|c|c|}
\hline Antibody & KL-1 & K17 & K13 & EMA & Vim. & SMA & S-100 & ER & c-erbB2 & bcl-2 & p53 & Ki-67 & p63 \\
\hline NT & + & $+{ }^{a}$ & + & + & - & $+{ }^{b}$ & - & + & - & + & - & - & $++^{a}$ \\
\hline DC & + & - & + & + & + & - & - & - & ++ & - & +++ & ++ & - \\
\hline SC & + & + & ++ & + & + & - & - & - & - & - & +++ & ++ & ++ \\
\hline CC & + & - & + & + & + & + & - & - & - & - & +++ & ++ & - \\
\hline
\end{tabular}

${ }^{a}$ Only the basal cells of the duct are positive for the antibody.

${ }^{b}$ Only myoepithelial cells are positive for the antibody.

EMA, epithelial membrane antigen; Vim., Vimentin; SMA, smooth muscle actin; NT, normal tissue; DC, invasive ductal carcinoma; SC, squamous carcinomatous element; CC, chondrosarcomatoid element.

ductal carcinoma or the cartilaginous component. Expression of smooth muscle actin was observed only in the normal myoepithelial cells and the cartilaginous component but not in the ductal carcinoma or the squamous component. All the three elements of the tumor exhibited a strong expression for p53 (more than 70\%) and Ki-67 (more than $40 \%)$. All the three elements were negative for estrogen receptor immunohistochemically. The results of the immunohistochemical study are summarized in Table 2.

\section{DNA Sequencing of p53 Gene}

The same point mutation was identified at the codon Y220C of exon 6 (transition A to G) in the three samples separately obtained from the invasive ductal carcinoma, squamous element and cartilaginous element of the tumor (Fig. 2). The point mutation was not discovered in the samples from normal ductal epithelium and normal stromal cells.

\section{DISCUSSION}

Carcinoma of the breast arises from the mammary glandular epithelium and shows ductal or lobular differentiation. However, a few cases of breast cancer transform into a non-glandular growth pattern and they are postulated as metaplasia of carcinoma. Here we reported an extremely rare case that coexhibited both squamous metaplasia and heterologous metaplasia.

It is very likely that genetic alterations in the individual tumor lead to variation in the phenotypic expression. If the several elements of metaplastic carcinoma were originated from entirely separate progenitor cells, disparities in the expression of p53 protein in the several components should be common. But if the several elements were form the same progenitor cell, the disparities would not be expected. Our immunohistochemical studies demonstrated a strong p53 expression among the three components in the tumor equally. It also suggested that the three components were derived from a common progenitor cell. The result of p53 mutation analysis in our studies further proved that there was the same point mutation at the same location among the three elements in the tumor. The results led us to conclude that the same progenitor cells would produce the three components, although they expressed different histologic

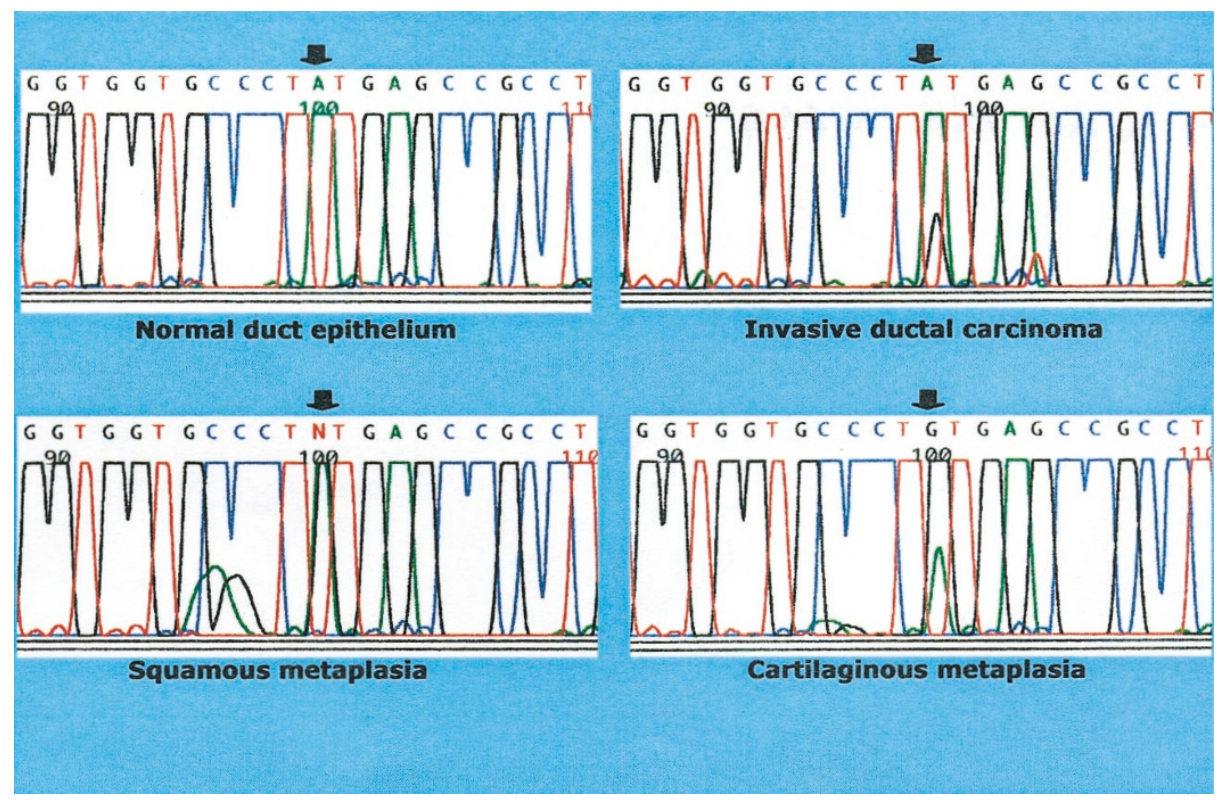

FIGURE 2. p53 sequence data of exon 6 in the metaplastic carcinoma of the breast. Y220C mutation (transition A to G) was detected at the same location in the three components of the tumor but not in the normal ductal epithelium. 
phenotypes. Furthermore, the results strongly suggested that p53 mutation occurred in the early phase of progression of the tumor.

Histogenesis of metaplastic carcinoma of the breast remains uncertain (7-9). Three different cell types had been observed in the normal duct of breast. They are superficial cells (luminal), basal cell (chief cells), and myoepithelial cells (10). In our case, the expression of keratin, cytokeratin 13, and epithelial membrane antigen were observed in both carcinomatous and sarcomatoid elements. It could be interpreted as an evidence for the epithelial origin of the two components. Cytokeratin 17 and p63 were reported being expressed in basal cells of the breast, prostate, salivary and lachrymal glands (1113) In our tumor, they expressed in the basal cells of normal duct and squamous element of the breast cancer. This expressive pattern was consistent with the hypothesis that the squamous metaplastic element exhibited the differentiation of the basal cells. The cartilaginous component immunohistochemically expressed both for epithelial markers and myoepithelial marker such as smooth muscle actin. This observation also led us to conclude that the sarcomatoid component of this tumor showed differentiation of myoepithelial cells. We considered that the tumor might have been derived from the same duct progenitor cells, and that these cells still remained a multipotential after a p53 point mutation. The lineage of cells bound for luminal cells differentiated to ductal carcinoma, cells for basal cells differentiated to squamous carcinomatous element, and cells for myoepithelial cells differentiated to chondrosarcomatoid element.

Recently, the expression of p63 were reported to have been found in a benign lesion of the prostate rather than in malignant lesions (14). Although positive expression was observed in normal ductal basal cells and not in malignant glandular epithelium In this case, a strong positive expression was noted in the malignant squamous component. Relative data in this aspect need to be accumulated in the future.

In conclusion, the three components in the metaplastic carcinoma of the breast might be originated from the same duct progenitor cells and p53 point mutation might occurred in the early phase of progression of the tumor.
Acknowledgment: We thank Emiko Taniguchi and Tomoko Kagiya for preparing histologic sections.

\section{REFERENCES}

1. Fisher ER, Gregorio RM, Palekar AS, Paulson JD. Mucoepidermoid and squamous cell carcinomas of breast with reference to squamous metaplasia and giant cell tumors. Am J Surg Pathol 1984;7:15-27.

2. Kaufman MW, Marti JR, Gallager HS, Hoehn JL. Carcinoma of the breast with pseudosarcomatous metaplasia. Cancer 1984;53:1908-17.

3. Hayashi I, Katsuda Y, Nomura Y, Tashiro H, Ookuma T. A case of carcinoma of the breast with squamous and cartilaginous metaplasia. Gan No Rinsho 1984;30:1924-30.

4. Pitts WC, Rojas VA, Gaffey MJ, Rouse RV, Estaban J, Frierson HF, et al. Carcinomas with metaplasia and sarcomas of the breast. Am J Clin Pathol 1991;95:623-32.

5. Lehmann U, Glockner S, Kleeberger W, von Wasielewski HF, Kreipe H. Detection of gene amplification in archival breast cancer specimens by laser-assisted microdissection and quantitative real-time polymerase chain reaction. Am J Pathol 2000;156:1855-64.

6. Kishikawa S, Shan L, Ogihara K, Utsunomiya H, Nakamura $\mathrm{M}$, Nakamura Y, et al. Overexpression and genetic abnormality of p53 in parathyroid adenoma. Pathol Int 1999;49: 853-7.

7. Wargotz ES, Norris HJ. Metaplastic carcinoma of the breast. IV. Squamous cell carcinoma of ductal origin. Cancer 1990; 65:272-6.

8. Wargotz ES, Norris HJ. Metaplastic carcinomas of the breast. III. Carcinosarcoma. Cancer 1989;64:1490-9.

9. Zhuang Z, Lininger RA, Man YG, Albuquerque A, Merino MJ, Tavassoli FA. Identical clonality of both components of mammary carcinosarcoma with differential loss of heterozygosity. Mod Pathol 1997;10:354-62.

10. Osborne MP. Breast anatomy and development. In: Harris JR, Lippman ME, Morrow M, Osborne CK, editors. Diseases of the breast. 2nd ed. Baltimore: Lippincott Williams \& Wilkins; 1999. p. 9.

11. Yang A, Kaghad M, Wang Y, Gillett E, Fleming MD, Dotsch V, et al. p63, a p53 homology at 3q27-29, encodes multiple products with transactivating, death-inducing, and dominant-negative activities. Mol Cell 1998;2:305-16.

12. Parsa R, Yang A, McKeon F, Green H. Association of p63 with proliferative potential in normal and neoplastic human keratinocytes. J Invest Dermatol 1999;113:1099-105.

13. Troyanowsky SM, Guelstein VI, Tchypysheva TA, Krutovskikh VA, Bannikov GA. Patterns of expression of keratin 17 in human epithelia: dependency on cell position. J Cell Sci 1989;93:419-26.

14. Sabina S, David W, James D, Beth I, Douglas L, Levi G, et al. p63 is a prostate basal cell marker and is required for prostate development. Am J Pathol 2000;157:1769-75. 